\section{Effects of Preconditioning and Fruit Maturity on the Occurrence of Soft Scald and Soggy Breakdown in 'Honeycrisp' Apples}

\author{
Renae E. Moran ${ }^{1}$ \\ Department of Plant, Soil and Environmental Sciences, University of Maine, \\ P.O. Box 179, Monmouth, ME 02459
}

\author{
Jennifer R. DeEll \\ Ontario Ministry of Agriculture, Food and Rural Affairs, P.O. Box 587, \\ Simcoe, Ontario, Canada N3Y 4N5
}

\author{
Dennis P. Murr \\ Department of Plant Agriculture, University of Guelph, Guelph, Ontario, \\ Canada N1G 2W1
}

Additional index words. Malus $\times$ domestica, storage disorders, bitter pit

\begin{abstract}
Preconditioning, holding fruit at 10, 17.5, or $21^{\circ} \mathrm{C}$ temperatures for up to 7 days before placement in cold storage, was inconsistent in its effect on soft scald and soggy breakdown in 'Honeycrisp' apples in Maine and Ontario. In Ontario, 4 days of preconditioning at $21^{\circ} \mathrm{C}$ increased soft scald in 1 year but had no effect in the next year. Five $d$ of preconditioning at $10{ }^{\circ} \mathrm{C}$ reduced soft scald and had no effect on soggy breakdown in 1 year but reduced it the next year. In Maine, 5 days preconditioning at $17.5{ }^{\circ} \mathrm{C}$ was effective in reducing soft scald and/or soggy breakdown in 2002 to 2007 when starch index at harvest was 5.9 to 7.2 . Seven days of preconditioning at $17.5^{\circ} \mathrm{C}$ increased soggy breakdown with an early harvest in two orchards but only in one of two orchards with a later harvest. This same preconditioning had no effect on soft scald with the first harvest but reduced it with the second. In the next year, the same preconditioning treatment increased soft scald and soggy breakdown with an early maturity but had no effect with a later maturity in one orchard but not in fruit from another. Conditions during preconditioning and subsequent cold storage temperatures varied from previous recommendations, and this may be why preconditioning was not consistent in our studies and in some cases increased chilling disorders.
\end{abstract}

'Honeycrisp' apples develop the disorders soft scald and soggy breakdown in cold storage, particularly at temperatures below $3{ }^{\circ} \mathrm{C}$ (Watkins et al., 2003). Soft scald is a low-temperature disorder that is characterized by sharply defined, irregularly shaped, brown lesions on the apple peel (Meheriuk et al., 1994; Snowdon, 1990). Damage can also extend into the flesh, and the lesions are often invaded by secondary infections. On the other hand, soggy breakdown is an internal disorder. The apple flesh develops moist,

Received for publication 10 June 2010. Accepted for publication 11 Sept. 2010.

Maine Ag. and Forestry Experiment Station number 3146 .

Funded in part by the New England Tree Fruit Research Committee, the Maine Agricultural Center, and the University of Maine Agricultural and Forest Experiment Station.

Mention of a trademark, proprietary product, or vendor does not constitute a guarantee or warranty of the product nor does it imply approval or disapproval to the exclusion of other products or vendors that may also be suitable.

${ }^{1}$ To whom reprint requests should be addressed; e-mailrmoran@maine.edu. does not work in some cases, but the inevitable variation in fruit maturity, environmental conditions during preconditioning, and subsequent storage temperature among different storage facilities may be part of the cause. The objective of this research was to evaluate effectiveness and consistency of preconditioning on occurrence of soft scald and soggy breakdown as well as the interaction of preconditioning with fruit maturity at harvest.

\section{Materials and Methods}

Ontario. 'Honeycrisp' apples were harvested from a commercial orchard located in Norfolk County, Ontario. The same orchard was used for all years of study. Trees were planted in 1998 on M.26 rootstock.

In 2003, fruit with either a low or high degree of red color were subjected to $2 \mathrm{~d}$ of preconditioning at either 10 or $20{ }^{\circ} \mathrm{C}$ or immediate transfer to $2.5^{\circ} \mathrm{C}$. $\mathrm{L}^{*}$ (measurement of lightness), $a^{*}$ [intensity of red $(a+)$ or green $(\mathrm{a}-)$ coloration], and $\mathrm{b}^{*}$ [intensity of yellow $(b+)$ or blue $(b-)$ coloration] was measured on 24 fruit of each color on the day of harvest with a Konica Minolta CR 400 Chroma Meter (Folio Instruments Inc., Kitchener, Ontario, Canada). Fruit from each treatment were subsequently stored in air at $2.5^{\circ} \mathrm{C}$. Three storage durations, $3,4.5$, and 6 months, were tested, but data from different storage durations were pooled for analysis because there was no effect on soft scald or soggy breakdown.

In 2004 and 2005, fruit were subjected to no preconditioning or $4 \mathrm{~d}$ of preconditioning at $21{ }^{\circ} \mathrm{C}$ followed by air storage at $1.5,3.0$, or $4.5^{\circ} \mathrm{C}$ for 5 months.

In 2006 and 2007, fruit were harvested on two different dates and in 2008 on one date. In each of these years, fruit were given a 5 -d preconditioning treatment at $10{ }^{\circ} \mathrm{C}$ followed by air storage at $3{ }^{\circ} \mathrm{C}$ for 4 or 6 months. Data from both storage durations were pooled for analysis because there was no effect on disorders.

Starch staining with iodine was measured on 10 fruit per replicate on each harvest date using a visual rating in which $1=$ all starch remaining and $8=$ no starch (Blanpied and Silsby, 1992). To measure internal ethylene concentration (IEC), a 3-mL gas sample was withdrawn from the core of each fruit using a syringe and injecting the sample into a Varian CP-3800 gas chromatograph (Varian Canada Inc., Mississauga, Ontario, Canada) equipped with a $0.5-\mathrm{mL}$ sample loop, flame ionization detector (FID), and $15 \mathrm{~m} \times 0.32$ mm Restek Rt-SPLOT ${ }^{\mathrm{TM}}$ capillary column (Chromatographic Specialties Inc., Brockville, Ontario, Canada). The injector, column, and detector temperatures were 120,35 , and $225{ }^{\circ} \mathrm{C}$, respectively. High-grade helium was used as the carrier gas at a flow rate of 0.37 $\mathrm{mL} \cdot \mathrm{s}^{-1}$ with a typical run time of $2 \mathrm{~min}$.

In each year, harvest date, storage temperature, storage duration, and preconditioning treatments were replicated three times with 15 fruit per replicate. The orchard was located in Norfolk County, Ontario. 
Table 1. Disorder incidence in 'Honeycrisp' apples after prestorage preconditioning of $7 \mathrm{~d}$ at a mean ambient temperature of $17^{\circ} \mathrm{C}$ and $2 \mathrm{months}$ air storage at $1^{\circ} \mathrm{C}$ in two orchards in Maine in 2008.

\begin{tabular}{|c|c|c|c|c|c|c|c|}
\hline \multirow[b]{2}{*}{ Harvest date } & \multirow[b]{2}{*}{ Orchard } & \multirow[b]{2}{*}{ Starch index ${ }^{y}$} & \multirow[b]{2}{*}{$\operatorname{IEC}\left(\mu \mathrm{L} \cdot \mathrm{L}^{-1}\right)^{\mathrm{x}}$} & \multirow[b]{2}{*}{ Days of preconditioning } & \multicolumn{3}{|c|}{ Percent incidence $^{z}$} \\
\hline & & & & & Soft scald & Soggy breakdown & Bitter pit \\
\hline \multirow{2}{*}{17 Sept. } & & & & 7 & $14 \mathrm{bc}$ & $15 \mathrm{a}$ & $0.5 \mathrm{bc}$ \\
\hline & 2 & $3.9 \mathrm{c}$ & $2.4 \mathrm{~b}$ & 0 & $2 \mathrm{bc}$ & $2 \mathrm{~b}$ & $2.2 \mathrm{bc}$ \\
\hline \multirow[t]{3}{*}{25 Sept. } & 1 & $6.9 \mathrm{a}$ & $8.6 \mathrm{a}$ & 0 & $35 \mathrm{a}$ & $0 \mathrm{~b}$ & $0.2 \mathrm{c}$ \\
\hline & & & & 7 & $1 \mathrm{c}$ & $0 \mathrm{~b}$ & $1.3 \mathrm{bc}$ \\
\hline & 2 & $6.6 \mathrm{a}$ & $7.3 \mathrm{ab}$ & 0 & $6 \mathrm{bc}$ & $3 \mathrm{~b}$ & $4.2 \mathrm{ab}$ \\
\hline Harvest $(\mathrm{H})$ & & 0.0001 & 0.0047 & & 0.8239 & 0.0980 & 0.8390 \\
\hline Orchard (O) & & 0.0237 & 0.1194 & & 0.0037 & 0.0007 & 0.0006 \\
\hline Preconditioning $(\mathrm{P})$ & & - & - & & 0.0237 & 0.0001 & 0.2076 \\
\hline $\mathrm{H} \times \mathrm{O}$ & & 0.1418 & 0.6005 & & 0.9428 & 0.0065 & 0.7514 \\
\hline $\mathrm{H} \times \mathrm{P}$ & & - & - & & 0.1378 & 0.0930 & 0.3474 \\
\hline $\mathrm{O} \times \mathrm{P}$ & & - & - & & 0.0561 & 0.0163 & 0.3646 \\
\hline
\end{tabular}

${ }^{\mathrm{z}}$ Disorder incidence was arcsine-transformed for analysis, but actual means are presented.

${ }^{\mathrm{y}}$ Starch index of $1=$ complete starch staining and $8=$ no staining with iodine.

${ }^{x} I E C$, internal ethylene concentration, was log-transformed for analysis, but actual means are presented.

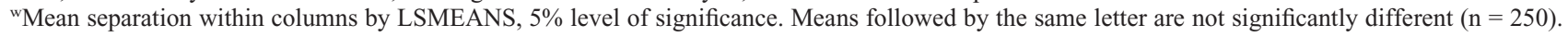

Maine. The effect of preconditioning was tested in 6 years using 'Honeycrisp' apples from an orchard located at the Maine Agricultural and Forest Experiment Station in Monmouth, ME. Trees, on M.26 rootstock, were planted in 1994 at a spacing of $2 \mathrm{~m}$ and were grown using standard cultural practices for the region. Fruit were placed in cold storage within $3 \mathrm{~h}$ of harvest at $1{ }^{\circ} \mathrm{C}$ or held at an average temperature of $17.5^{\circ} \mathrm{C}$ for $5 \mathrm{~d}$ before placement in cold storage. Temperature during preconditioning was not controlled and ranged from 15.5 to $20.5{ }^{\circ} \mathrm{C}$ but varied little from year to year. Additional delays of 7 and $10 \mathrm{~d}$ were tested in 2007. Storage duration was 4 to 5 months in 2002 to 2005 and 2 to 3 months in 2006 and 2007. Occurrence of soft scald, soggy breakdown, and bitter pit was measured $7 \mathrm{~d}$ after removal from cold storage in 2002 through 2005 and $1 \mathrm{~d}$ after in subsequent years. Soft scald was defined as external browning and soggy breakdown as internal browning in the cortex with a partial or complete ring of healthy tissue near the surface.

In 2008, preconditioning of $7 \mathrm{~d}$ was tested using fruit from two harvest dates and two locations, Monmouth (Orchard 1) and Turner (Orchard 2), ME. Orchard 1 in 2008 was the same orchard used in previous years and in 2009 was a younger orchard planted in 2002 with M.26 rootstock. In 2009, fruit from one harvest date but two stages of maturity were subjected to 7-d preconditioning. To create two different stages of maturity on the same day, ethephon (2-chloroethylphosphonic acid; Rhone-Poulenc, Research Triangle Park, NC) at $300 \mu \mathrm{L} \cdot \mathrm{L}^{-1}$ was applied to a block of trees in each orchard. Ethephon was applied 5 Sept. with $10 \mu \mathrm{L} \cdot \mathrm{L}^{-1}$ 1-naphthaleneacetic acid (NAA; AMVAC Chemical Corporation, Los Angeles, CA) to Orchard 1 and 1 Sept. with $15 \mu \mathrm{L} \cdot \mathrm{L}^{-1}$ NAA to Orchard 2. Ethephon was reapplied 4 Sept. to Orchard 2 at the same rate with $10 \mu \mathrm{L} \cdot \mathrm{L}^{-1} \mathrm{NAA}$. Harvest dates and starch indices are listed in Table 1. Temperature during preconditioning was similar to previous years. Disorders were measured after 2.5 months of air storage at $1{ }^{\circ} \mathrm{C}$.

Starch index and IEC were measured on a total of 10 fruit in 2002 and 2003 and 10 fruit per replication in the next years. Starch index was measured using the same method as in Ontario. To measure IEC, a 1-mL gas sample was withdrawn from the core of each fruit using a syringe and injecting the sample into a Shimadzu GC-8A gas chromatograph (Kyoto, Japan) equipped with an FID and $450 \times 3-\mathrm{mm}$ stainless steel column packed with activated alumina. The injector and detector temperatures were $200{ }^{\circ} \mathrm{C}$, and the column temperature was $80^{\circ} \mathrm{C}$. Flow rates for nitrogen, air, and hydrogen were 90, 230, and $60 \mathrm{~mL} \cdot \mathrm{min}^{-1}$, respectively.

There were five replications of 50 fruit each for each treatment combination. Each replication was sourced from a minimum of two trees.

Statistical analyses. Data from both locations were subjected to analysis of variance by the GLM procedure and means separation by LSMeans using SAS software Version 9.1 (SAS Institute, Inc., Cary, NC).

\section{Results and Discussion}

Ontario. In 2003, the starch index at harvest was 3.8 for red-colored fruit and 2.3 for fruit with less red color. For highly redcolored fruit and fruit with less red color, IEC was 0.61 and $0.12 \mu \mathrm{L} \cdot \mathrm{L}^{-1}$, respectively. $\mathrm{L}^{*} \mathrm{a}^{*}$ $\mathrm{b}^{*}$ scores for highly red colored fruit were 42.85 (SEM 0.92), 23.67 (SEM 0.74), and 13.55 (SEM 0.33 ), respectively. $\mathrm{L}^{*} \mathrm{a}^{*} \mathrm{~b}^{*}$ scores for fruit with less red color were 53.43 (SEM 0.71 ), 6.87 (SEM 0.79), and 19.23 (SEM 0.33), respectively. Soft scald incidence was $2 \%$ (data not shown) and was low most likely as a result of early harvest based on starch index below 4.0. Harvest at an earlier maturity, starch index 5, can reduce incidence of soft
Table 2. Soft scald incidence in 'Honeycrisp' apples after prestorage preconditioning of $4 \mathrm{~d}$ at $21{ }^{\circ} \mathrm{C}$ followed by 5 months air storage at three temperatures in Ontario in 2004 and 2005.

\begin{tabular}{lcc}
\hline & \multicolumn{2}{c}{ Soft scald incidence $(\%)$} \\
\cline { 2 - 3 } Main effects & 2004 & 2005 \\
\hline Temperature $\left({ }^{\circ} \mathrm{C}\right)$ & 13 & $18 \mathrm{a}$ \\
1.5 & 13 & $10 \mathrm{~b}$ \\
3.0 & 18 & $9 \mathrm{~b}$ \\
$\quad 4.5$ & & \\
Preconditioning (P) & $9 \mathrm{~b}^{\mathrm{z}}$ & 11 \\
$\quad$ None & $21 \mathrm{a}$ & 14 \\
$4 \mathrm{~d}$ & & \\
& & \\
Analysis of variance & & \\
$\quad \mathrm{P}$ & 0.0126 & 0.3012 \\
$\quad$ Temperature (T) & 0.5282 & 0.0031 \\
$\quad \mathrm{P} \times \mathrm{T}$ & 0.9324 & 0.1091 \\
\hline
\end{tabular}

${ }^{2}$ Means separation by LSMEANS, 5\% level of significance. Means followed by the same letter are not significantly different. Disorder incidence was arcsine-transformed for analysis, but actual means are presented $(n=45)$.

scald but is not $100 \%$ effective, particularly with storage at a temperature below $3{ }^{\circ} \mathrm{C}$ (Watkins et al., 2003). Incidence of soft scald was $2 \%$ to $3 \%$ with $2 \mathrm{~d}$ of preconditioning at either 10 or $20^{\circ} \mathrm{C}$, which was not significantly different from fruit that were not preconditioned. Bitter pit incidence was very high at $20 \%$ in the untreated control, $28 \%$ with preconditioning at $10{ }^{\circ} \mathrm{C}$, and $12 \%$ with preconditioning at $20{ }^{\circ} \mathrm{C}$. Neither preconditioning treatment increased bitter pit more than in control fruit, but bitter pit was greater in fruit from the $10^{\circ} \mathrm{C}$ preconditioning $(P=$ 0.0020 ) than with $20^{\circ} \mathrm{C}$. Fruit with greater red coloration had a greater incidence of soft scald, $4 \%$, compared with fruit with poorly developed color, $1 \%(P=0.0060)$. There was no interaction between fruit color and preconditioning and no effect of skin color on bitter pit.

In 2004 and 2005, fruit were harvested when starch index was 4.4 and 6.0 , respectively. Internal ethylene concentration was 
Table 3. Disorder incidence in Ontario 'Honeycrisp' apples after $5 \mathrm{~d}$ preconditioning at $10{ }^{\circ} \mathrm{C}$ and 4 or $6^{z}$ months air storage at $3{ }^{\circ} \mathrm{C}$ in 2006 and 2007 and 3 or $6^{z}$ months at $0.5^{\circ} \mathrm{C}$ in 2008 .

\begin{tabular}{|c|c|c|c|c|c|c|c|c|}
\hline \multirow[b]{2}{*}{ Harvest } & \multirow[b]{2}{*}{ Preconditioning } & \multicolumn{2}{|c|}{ Soft scald } & \multicolumn{3}{|c|}{ Soggy breakdown } & \multicolumn{2}{|c|}{ Bitter pit } \\
\hline & & 2007 & 2008 & 2006 & 2007 & 2008 & 2006 & 2007 \\
\hline$\overline{1}$ & $5 \mathrm{~d}$ & $1 \mathrm{~b}$ & $14 \mathrm{~b}$ & 5 & $0 \mathrm{~b}$ & 3 & 12 & $3 \mathrm{bc}$ \\
\hline 2 & $5 \mathrm{~d}$ & $0 \mathrm{~b}$ & - & 10 & $0 \mathrm{~b}$ & - & 5 & $9 \mathrm{a}$ \\
\hline \multicolumn{9}{|c|}{ Analysis of variance } \\
\hline \multicolumn{2}{|c|}{ Harvest $(\mathrm{H})$} & 0.7184 & - & 0.2800 & 0.0480 & - & 0.0746 & 0.9947 \\
\hline
\end{tabular}

${ }^{\mathrm{z}}$ Data from two storage durations were pooled for analysis.

${ }^{y}$ No soft scald occurred in 2006 and no bitter pit in 2008. Means separation within columns by LSMEANS, 5\% level of significance. Means followed by the same letter are not significantly different $(n=45)$. Disorder incidence was arcsine-transformed for analysis, but actual means are presented.

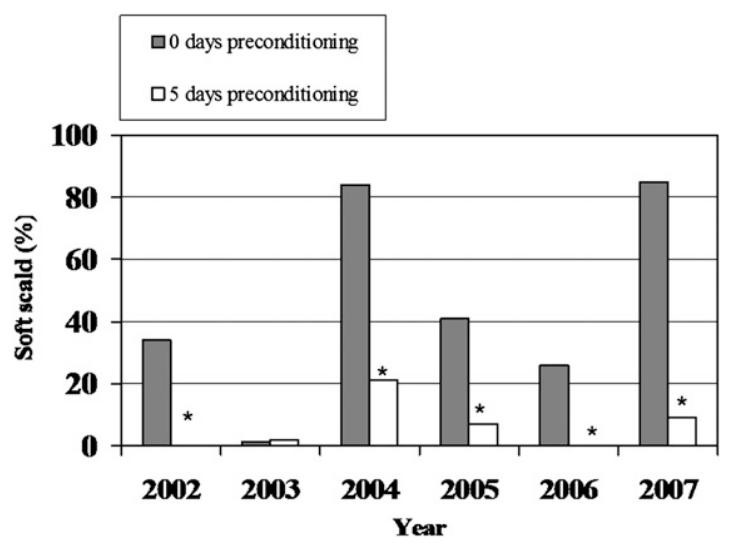

Fig. 1. Incidence of soft scald after 0 or $5 \mathrm{~d}$ of preconditioning at a mean ambient temperature of $17.5^{\circ} \mathrm{C}$ followed by 3 to 5 months cold storage at $1{ }^{\circ} \mathrm{C}$ in Maine from 2002 to $2007(\mathrm{n}=250)$. The asterisk indicates a significant difference from the untreated control based on analysis of variance LSMEANS $(P=0.05)$ within each year.

0.8 and $2.9 \mu \mathrm{L} \cdot \mathrm{L}^{-1}$ at harvest, respectively. Four d of preconditioning increased soft scald in 2004 but had no effect in 2005 (Table 2. Storage temperature had no effect in 2004, but warmer temperatures reduced soft scald in 2005. Preconditioning did not affect soggy breakdown or bitter pit, which were negligible (data not shown).

In 2006, starch index at harvest was 4.5 and 6.7 , and IEC was 10.9 and $28.1 \mu \mathrm{L} \cdot \mathrm{L}^{-1}$, respectively. In 2007, fruit were harvested when starch index was 6.0 and 7.2, and IEC was 4.4 and $1.9 \mu \mathrm{L} \cdot \mathrm{L}^{-1}$, respectively. Fruit were harvested once in 2008 when starch index was 5.4 and IEC was $10.7 \mu \mathrm{L} \cdot \mathrm{L}^{-1}$. Occurrence of soft scald was negligible in 2006 and unaffected by $5 \mathrm{~d}$ of preconditioning (data not shown). In 2007, soft scald incidence was also low, and preconditioning decreased it with no harvest date interaction (Table 3). Soft scald was severe in 2008 and preconditioning substantially reduced it, although storage temperature was colder than in previous years and below the recommended range (Watkins et al., 2003). Soggy breakdown was unaffected by preconditioning in 2006 or 2008. In 2007, preconditioning reduced soggy breakdown in the first harvest, but none occurred in fruit from the second harvest. Bitter pit was unaffected by preconditioning in 2006 and none occurred in 2008 (data not shown). In 2007, preconditioning had no effect on bitter pit in fruit from the first harvest but increased bitter pit in fruit from the second harvest.

Maine. Starch index at harvest was 6.9, 7.8, 5.9, 6.7, 7.0, and 7.2 in 2002, 2003, 2004, 2005, 2006, and 2007, respectively, and internal ethylene was $6,32,0,0,8$, and 11 $\mu \mathrm{L} \cdot \mathrm{L}^{-1}$ in each year, respectively. Preconditioning reduced soft scald in Years 2002 through 2007 except 2003 when very little soft scald occurred (Fig. 1). In each of these years, harvest maturity was generally late based on starch index, and preconditioning duration and temperature were similar. The similar manner in which fruit were harvested and preconditioned may have contributed to the consistency of preconditioning.

Five $d$ preconditioning was sufficient to completely prevent soft scald in 2002 and 2006 (Fig. 1). In years with high susceptibility, $5 \mathrm{~d}$ reduced but did not eliminate soft scald. Preconditioning for 7 and $10 \mathrm{~d}$ in 2007 resulted in $0.4 \%$ and $0 \%$ soft scald, respectively, indicating that a longer duration was needed in this year when susceptibility was very high. Soft scald incidence was in most cases greater than in Ontario but consistent with advanced maturity at harvest and storage temperature below $2{ }^{\circ} \mathrm{C}$ (Watkins et al., 2003). Soggy breakdown was difficult to measure in most years because of the severe soft scald preventing distinction of the two disorders. Bitter pit was generally low and unaffected by preconditioning except in 2005 when it was slightly increased from $1 \%$ to $2 \%$.

In 2008, fruit maturity at harvest was tested as a possible factor contributing to preconditioning failure such as in Ontario when preconditioning increased soft scald in a year in which fruit were harvested at a starch index of 2 to 4 . Starch index was significantly less in the first harvest compared with the second in both orchards (Table 1). Starch breakdown was delayed in Orchard 2 compared with Orchard 1. Internal ethylene concentration was greater in the second harvest compared with the first but similar in both orchards. Harvest date did not affect soft scald, but orchard and preconditioning did with a marginally significant interaction $(P=0.0561)$. With Orchard 1, preconditioning reduced soft scald in fruit from the second harvest but not the first. Soft scald incidence was low in Orchard 2 and unaffected by preconditioning with either harvest. There was a significant orchard effect as well as an interaction among orchard, harvest date, and preconditioning in their effect on soggy breakdown. Soggy breakdown incidence was low in untreated fruit from both harvests and both orchards. Preconditioning increased soggy breakdown in fruit from both harvests in Orchard 2 and in fruit from the first harvest in Orchard 1. There was no effect on fruit from the second harvest in Orchard 1. In this year, soggy breakdown was easily distinguished from soft scald, unlike previous years when soft scald was severe. Fruit that developed soggy breakdown did not always develop soft scald. Bitter pit was unaffected by preconditioning in Orchard 1. Orchard 2 had greater bitter pit than Orchard 1 , and this was increased by preconditioning with the first harvest but not the second. It is not clear why there was an orchard effect on bitter pit occurrence because foliar levels of calcium were similar in the two orchards (1.1\%).

In 2009, ethephon hastened starch breakdown in both orchards, and starch breakdown was more advanced in Orchard 1 than in Orchard 2 (Table 4). Ethephon increased IEC 
Table 4. Disorder incidence in 'Honeycrisp' apples after prestorage preconditioning of $7 \mathrm{~d}$ at a mean ambient temperature of $17^{\circ} \mathrm{C}$ and 3 months air storage at $1{ }^{\circ} \mathrm{C}$ in two orchards in Maine in 2009.

\begin{tabular}{|c|c|c|c|c|c|c|c|}
\hline \multirow[b]{2}{*}{ Ethephon $^{2}$} & \multirow[b]{2}{*}{ Orchard } & \multirow[b]{2}{*}{ Starch index ${ }^{y}$} & \multirow[b]{2}{*}{$\operatorname{IEC}\left(\mu \mathrm{L} \cdot \mathrm{L}^{-1}\right)^{\mathrm{x}}$} & \multirow[b]{2}{*}{ Days of preconditioning } & \multicolumn{3}{|c|}{ Percent incidence $^{\mathrm{w}}$} \\
\hline & & & & & Soft scald & Soggy breakdown & Bitter pit \\
\hline \multirow{2}{*}{ None } & & & & 7 & $8 \mathrm{a}$ & $5 \mathrm{a}$ & $27 \mathrm{ab}$ \\
\hline & 2 & $1.8 \mathrm{~d}$ & $0.0 \mathrm{~b}$ & 0 & $0 \mathrm{~b}$ & $0 \mathrm{~b}$ & $5 \mathrm{~d}$ \\
\hline \multirow[t]{3}{*}{ Yes } & 1 & $6.4 \mathrm{a}$ & $22.0 \mathrm{a}$ & 0 & $0 \mathrm{~b}$ & $1 \mathrm{~b}$ & $12 \mathrm{~cd}$ \\
\hline & & & & 7 & $0 \mathrm{~b}$ & $0 \mathrm{~b}$ & $19 \mathrm{bc}$ \\
\hline & 2 & $4.6 \mathrm{~b}$ & $1.3 \mathrm{~b}$ & 0 & $0 \mathrm{~b}$ & $0 \mathrm{~b}$ & $6 \mathrm{~d}$ \\
\hline \multicolumn{8}{|l|}{ Analysis of variance } \\
\hline Ethephon (E) & & 0.0001 & 0.0089 & & 0.0017 & 0.0001 & 0.0099 \\
\hline Orchard $(\mathrm{O})$ & & 0.0001 & 0.0068 & & 0.0017 & 0.0001 & 0.0001 \\
\hline Preconditioning $(\mathrm{P})$ & & - & - & & 0.0032 & 0.0001 & 0.2430 \\
\hline $\mathrm{E} \times \mathrm{O}$ & & 0.0066 & 0.0137 & & 0.0003 & 0.0001 & 0.0020 \\
\hline $\mathrm{E} \times \mathrm{P}$ & & - & - & & 0.0138 & 0.0001 & 0.1837 \\
\hline $\mathrm{O} \times \mathrm{P}$ & & - & - & & 0.0138 & 0.0001 & 0.4353 \\
\hline $\mathrm{E} \times \mathrm{O} \times \mathrm{P}$ & & - & - & & 0.0032 & 0.0001 & 0.2567 \\
\hline
\end{tabular}

${ }^{2}$ Ethephon at a rate $300 \mu \mathrm{L} \cdot \mathrm{L}^{-1}$ and 1-naphthaleneacetic acid at a rate of $10 \mu \mathrm{L} \cdot \mathrm{L}^{-1}$ was applied once to Orchard 1 and twice to Orchard 2.

${ }^{\mathrm{y}} \mathrm{Starch}$ index of $1=$ complete starch staining and $8=$ no staining with iodine.

${ }^{x}$ IEC, internal ethylene concentration, was log-transformed for analysis, but actual means are presented.

wDisorder incidence was arcsine-transformed for analysis, but actual means are presented.

${ }^{\vee}$ Mean separation within columns by LSMEANS, $5 \%$ level of significance. Means followed by the same letter are not significantly different $(\mathrm{n}=250)$.

in fruit from Orchard 1 but not in Orchard 2. Very low incidence of soft scald occurred in 2009. Preconditioning increased soft scald and soggy breakdown incidence with the earlier maturity but only in fruit from Orchard 1. With the later maturity, preconditioning did not affect either disorder. Bitter pit was more severe than in previous years, particularly with the earlier maturity. Preconditioning increased bitter pit, but only in fruit from Orchard 2 with the earlier maturity.

In this study, preconditioning was inconsistent in affecting soft scald and soggy breakdown of 'Honeycrisp' from year to year, within a year, and between orchards. In cultivars other than 'Honeycrisp', preconditioning can increase, decrease, or have no effect on soft scald or soggy breakdown depending on its duration, fruit maturity at harvest, and unexplainable seasonal variation (Harley and Fisher, 1930; Plagge and Maney, 1937). Soft scald incidence in 'Honeycrisp' apples has been shown to be negatively related to precipitation during 90 to $120 \mathrm{~d}$ from bloom (Moran et al., 2009), but it is not clear if weather variables are related to the inconsistency in preconditioning.

Previous reports indicate that soft scald is reduced by preconditioning for $7 \mathrm{~d}$ at $10{ }^{\circ} \mathrm{C}$ followed by storage at 0.5 or $2.5^{\circ} \mathrm{C}$ (Watkins et al., 2004) and by preconditioning at $20^{\circ} \mathrm{C}$ and storage at 3 or $5^{\circ} \mathrm{C}$ (DeLong et al., 2004). Shorter preconditioning periods were used in Ontario followed by storage at temperatures ranging from 0.5 to $4.5^{\circ} \mathrm{C}$, and subsequent cold storage at $1{ }^{\circ} \mathrm{C}$ was used in Maine. Our conditions varied from conditions in previous trials, and this may be why preconditioning was not consistent in our studies and in some cases increased chilling disorders.

Greater reduction in soggy breakdown can occur with warmer preconditioning temperatures from 10 to $30{ }^{\circ} \mathrm{C}$ but not with increasing duration from 0 to $6 \mathrm{~d}$ (DeLong et al., 2009). However, in another study (Watkins et al., 2004), preconditioning at $10{ }^{\circ} \mathrm{C}$ was effective in preventing soggy breakdown. A preconditioning temperature of $10{ }^{\circ} \mathrm{C}$ either had no effect or decreased soggy breakdown in Ontario (Table 3), but in Maine, $17{ }^{\circ} \mathrm{C}$ increased the disorder in some cases but not others (Tables 1 and 4).

There is an interaction between temperature during preconditioning and its duration in which warmer temperatures are more effective in reducing soft scald than cooler temperatures when duration is $6 \mathrm{~d}$ or less (DeLong et al., 2009). However, an increase or no reduction in soft scald occurred in years when a preconditioning temperature of $21^{\circ} \mathrm{C}$ was used for $4 \mathrm{~d}$ (Table 2), whereas in later years when $10^{\circ} \mathrm{C}$ was used, there was either a reduction in soft scald or no occurrence (Table 3 ). This suggests that other factors may be interacting with preconditioning.

An increase or lack of effect on soft scald and/or soggy breakdown with preconditioning was associated with an early harvest in Maine in Orchard 1 but not Orchard 2, indicating orchard factors contribute to the variability in response to preconditioning. An increase with preconditioning also occurred in Ontario but was not associated with an early harvest date in years when more than one harvest date was evaluated. The effect of harvest date and preconditioning has been previously reported, but maturity at harvest was more advanced based on starch index (Watkins et al., 2004) than in our study or was not reported (DeLong et al., 2004). The increased soggy breakdown in Maine was not associated with a particular stage of maturity, making it difficult to predict the effectiveness of preconditioning in pre- venting or reducing soft scald and soggy breakdown.

\section{Literature Cited}

Blanpied, G.D. and K. Silsby. 1992. Predicting harvest date windows for apples. Cornell Univ. (Ithaca, N.Y.) Info. Bul. 221.

DeLong, J.M., R.K. Prange, and P.A. Harrison. 2004. The Influence of pre-storage delayed cooling on quality and disorder incidence in 'Honeycrisp' apple fruit. Postharvest Biol. Technol. 34:353-358.

DeLong, J.M., R.K. Prange, W.C. Schotsmans, D.S. Nichols, and P.A. Harrison. 2009. Determination of the optimal prestorage delayed cooling regime to control disorders and maintain quality in 'Honeycrisp' apples. J. Hort. Sci. Biotechnol. 84:410-414.

Harley, C.P. and D.F. Fisher. 1930. A study of the internal atmosphere of apples in relation to soft scald. Proc. Amer. Soc. Hort. Sci. 27: 271-275.

Meheriuk, M., R.K. Prange, P.D. Lidster, and S.W. Porritt. 1994. Postharvest disorders of apples and pears. Agr. and Agri-Food Canada Pub. 1737/E.

Moran, R.E., J.R. DeEll, and W. Halteman. 2009. Effects of preharvest precipitation, air temperature and humidity on the occurrence of soft scald in 'Honeycrisp' apples. HortScience 44: 1645-1647.

Plagge, H.H. and T.J. Maney. 1937. Factors influencing the development of soggy break-down in apples. J. Agr. Res. 55:759-764.

Snowdon, A.L. 1990. A color atlas of post-harvest diseases and disorders of fruits and vegetables. Vol. 1. CRC Press, Boca Raton, FL.

Watkins, C.B., J.F. Nock, and K.A. Iungerman. 2003. Harvest date effects on maturity, quality and storage disorders of Honeycrisp apples from the Champlain Valley. New York Fruit Quarterly 11:23-26.

Watkins, C.B., J.F. Nock, S.A. Weis, S. Jayanty, and R.M. Beaudry. 2004. Storage temperature, diphenylamine, and pre-storage delay effects on soft scald, soggy breakdown and bitter pit of 'Honeycrisp' apples. Postharvest Biol. Technol. 32:213-221. 